\title{
ARTICLE OPEN \\ Investigating the association between obesity and asthma in 6- to 8-year-old Saudi children: a matched case-control study
}

\author{
Mahmoud Nahhas ${ }^{1}$, Raj Bhopal ${ }^{2}$, Chantelle Anandan ${ }^{1}$, Rob Elton ${ }^{3}$ and Aziz Sheikh ${ }^{1,4}$
}

\begin{abstract}
BACKGROUND: Previous studies have demonstrated an association between obesity and asthma, but there remains considerable uncertainty about whether this reflects an underlying causal relationship.

AIMS: To investigate the association between obesity and asthma in pre-pubertal children and to investigate the roles of airway obstruction and atopy as possible causal mechanisms.

METHODS: We conducted an age- and sex-matched case-control study of 1,264 6- to 8-year-old schoolchildren with and without asthma recruited from 37 randomly selected schools in Madinah, Saudi Arabia. The body mass index (BMI), waist circumference and skin fold thickness of the 632 children with asthma were compared with those of the 632 control children without asthma. Associations between obesity and asthma, adjusted for other potential risk factors, were assessed separately in boys and girls using conditional logistic regression analysis. The possible mediating roles of atopy and airway obstruction were studied by investigating the impact of incorporating data on sensitisation to common aeroallergens and measurements of lung function.

RESULTS: BMI was associated with asthma in boys (odds ratio $(\mathrm{OR})=1.14,95 \%$ confidence interval $(\mathrm{Cl}), 1.08-1.20$; adjusted $\mathrm{OR}=1.11,95 \% \mathrm{Cl}, 1.03-1.19)$ and girls $(\mathrm{OR}=1.37,95 \% \mathrm{Cl}, 1.26-1.50$; adjusted $\mathrm{OR}=1.38,95 \% \mathrm{Cl}, 1.23-1.56)$. Adjusting for forced expiratory volume in $1 \mathrm{~s}$ had a negligible impact on these associations, but these were attenuated following adjustment for allergic sensitisation, particularly in girls (girls: $\mathrm{OR}=1.25 ; 95 \% \mathrm{Cl}, 0.96-1.60$; boys: $\mathrm{OR}=1.09,95 \% \mathrm{Cl}, 0.99-1.19$ ).

CONCLUSIONS: BMI is associated with asthma in pre-pubertal Saudi boys and girls; this effect does not appear to be mediated through respiratory obstruction, but in girls this may at least partially be mediated through increased risk of allergic sensitisation.
\end{abstract}

npj Primary Care Respiratory Medicine (2014) 24, Article number: 14004; doi:10.1038/npjpcrm.2014.4; published online 5 June 2014

\section{INTRODUCTION}

The substantial parallel increases in the prevalence of obesity ${ }^{1-5}$ and asthma ${ }^{6-8}$ observed over recent decades have led to the suggestion that obesity may be causally implicated in the risk of developing asthma. ${ }^{9-11}$ This line of enquiry began with the study of female nurses enrolled in the Nurses' Health Study cohort, which found a strong, dose-dependent relationship between an increase in body mass index (BMI) and adult-onset asthma. ${ }^{12}$ Investigations into the association between obesity and asthma have subsequently been extended to both male and female adults, ${ }^{13}$ adolescents ${ }^{14-16}$ and young children, ${ }^{17}$ other populations of European origin ${ }^{9,18-20}$ and some other ethnic groups. ${ }^{17}$ Overall, this body of work has confirmed the original observationnamely that obesity is associated with an increased risk of developing asthma, ${ }^{15}$ particularly in post-pubertal females. ${ }^{21}$ What is, however, far less clear is whether this reflects a causal relationship between the two and, if so, what the underlying mechanisms might be.

Judgements on causal inference can be greatly aided by studying biological mechanisms $s^{22}$ and it is therefore welcome that the epidemiological evidence has triggered a substantial body of mechanistic work in both animal and human populations. ${ }^{23,24}$ Broadly speaking, this work has converged on studying the role of common genes, ${ }^{25,26}$ fetal programming, ${ }^{27}$ sex hormones, ${ }^{11,27,28}$ respiratory obstruction, ${ }^{29}$ bronchial hyper-reactivity ${ }^{21}$ and changes in immunological and inflammatory responses. ${ }^{11,26,27}$ This body of work has, however, thus far failed to generate any clear insights into possible biological pathways, possibly reflecting the fact that different mechanisms may be implicated in different population subgroups. It has therefore been suggested that age- and genderspecific investigations be undertaken in an attempt to progress understanding on possible causal pathways. ${ }^{21}$

We sought to contribute to this important area of enquiry by undertaking the first study of obesity and asthma in a Middle Eastern population. We investigated the association between obesity and asthma in pre-pubertal school-aged children, undertaking separate analyses in boys and girls, with a view to understanding the possible aetiological roles of physiological (i.e., respiratory obstruction) and immunological (i.e., allergic sensitisation) mechanisms.

\section{MATERIALS AND METHODS}

Ethical considerations

Permission was obtained from the education authorities in Madinah (General Directors) and School Health Departments in the Ministry of Education, Riyadh, Saudi Arabia, and from head-teachers of participating schools. Parents gave their signed, informed consent to their child's participation. All data had identifiers removed to minimise the risk of inadvertently breaching confidentiality.

\footnotetext{
${ }^{1}$ Allergy and Respiratory Research Group, Centre for Population Health Sciences, Medical School, The University of Edinburgh, Edinburgh, UK; ${ }^{2}$ Bruce and John Usher Professor of Public Health, Centre for Population Health Sciences, Medical School, The University of Edinburgh, Edinburgh, UK; ${ }^{3}$ Centre for Population Health Sciences, Medical School, The University of Edinburgh, Edinburgh, UK and ${ }^{4}$ Division of General Internal Medicine and Primary Care, Brigham and Women's Hospital/Harvard Medical School, Boston, MA, USA. Correspondence: A Sheikh (aziz.sheikh@ed.ac.uk)

Received 29 September 2013; revised 28 February 2014; accepted 1 March 2014
} 


\section{Design}

We conducted an age- and sex-matched case-control study of 1,264 schoolchildren with and without asthma. Children aged 6-8 years were recruited from 37 randomly selected schools in Madinah, Saudi Arabia. These children were identified from our linked cross-sectional study of over 5,000 children in whom we found an asthma prevalence of $23.6 \%$ (95\% confidence interval $(\mathrm{Cl}), 21.3,26.0)$; this group of children provided a sampling frame for this investigation. ${ }^{30}$ For this phase of work, we compared BMI, triceps skin fold thickness (TSFT) and waist circumferences (WCs) in children with a history of symptoms indicative of asthma (cases) with individually age- and sex-matched children without such a history (controls), factoring respiratory function and allergic sensitisation into the analyses. Pilot work confirmed the feasibility of undertaking this research.

\section{Setting}

Madinah is a city in the west of Saudi Arabia, with an area of $589 \mathrm{~km}^{2}$ which lies approximately $190 \mathrm{~km}$ from the Red Sea coast. It has a population of over 1.5 million people, approximately $5 \%$ of the total of 21.4 million residents in Saudi Arabia. ${ }^{31}$

\section{Recruitment of schools and students}

Lists of boys' and girls' primary schools were obtained from the General Directorate of Education of the Madinah region. Schools were then stratified according to the five geographical areas of Madinah and students' gender and a random sample of 37 schools (i.e., 8 girls' and 29 boys' schools) were approached. We invited the schools to participate with a letter of explanation to the head-teachers outlining the purpose of the study and the procedures that were to be employed.

Eligible children were those aged 6-8 years who had been resident in Madinah for at least 1 year prior to the start of the study. All eligible subjects were invited to participate via a letter and a consent form sent by the school to their parents.

\section{Identification of cases and controls}

The parents of all recruited children were asked to complete a questionnaire incorporating validated questions from the International Study of Asthma and Allergies in Childhood (ISAAC) ${ }^{32}$ that had previously been adapted for use in Arab populations. ${ }^{33}$ Cases were defined as children who were identified by parents as those who had 'ever had wheeze'; $; 0,34-36$ controls were defined as those children, matched for age and sex, who had according to their parents 'never had wheeze' as reported using the same instrument.

\section{Measures of obesity}

Our primary measure of obesity was $\mathrm{BMI}^{37}$ but, in addition, we measured weight, TSFT and WC. Children were asked to wear normal light clothing during measurements and to take off their shoes. Measurements of height to enable calculation of BMI (which was calculated as weight $(\mathrm{kg})$ divided by the square of height in metres $\left(\mathrm{kg} / \mathrm{m}^{2}\right)$ ), weight, TSFT and WC were recorded in the schools by trained members of the health-care team who were unaware of whether children had asthma or not. Height was measured with a portable stadiometer (SECA Leicester height measure, SECA, Birmingham, UK) using the method described by Tanner et al. ${ }^{38}$ Measurements were made to the nearest $0.1 \mathrm{~cm}$.

Children were weighed and measured separately from their classmates. Weight was measured using SECA Mechanical Column Scales, with measurements being recorded to the nearest $0.1 \mathrm{~kg}$.

We used BMI percentiles for girls and boys per age as a measure of standardised weight. As there are no reference data available for Saudi children, we used the Center for Disease Control and Prevention (CDC) BMI-for-age growth charts for girls and boys. ${ }^{39}$ According to these charts, underweight was defined as a BMI less than the 5th centile, healthy weight was defined as a BMI between the 5th and the 85th centile, overweight was defined as a BMI between the 85th and 94th centiles and obese was defined as a BMI equal to or greater than the 95th centile.

TSFT was measured three times to the nearest millimetre with a Holtain Skinfold Caliper (Holtain, Crymych, UK) on the right arm. The triceps skin fold locus was defined as being halfway between the acromion and olecranon on the back of the arm measured with the elbow bent. ${ }^{40,41}$ TSFT was used mainly to determine relative obesity and the percentage of body fat. ${ }^{40,41}$

WC was measured to the nearest centimetre with a Lufkin flexible steel tape measure (Apex Tool Group, Sparks, MD, USA), with children in the standing position after gentle expiration. The following anatomical landmarks were used: laterally, midway between the lowest portion of the rib cage and iliac crest; and anteriorly, midway between the xiphoid process of the sternum and the umbilicus. ${ }^{42}$

\section{Potential confounders}

The parental questionnaire provided information on the following potential confounders:

- Parental age

- Parental education

- Parental smoking status

- Number of siblings

- Place of birth

- Breastfeeding

- Medications administered (i.e., antibiotics and paracetamol)

- Exposure to pets and farm animals

- Food and other lifestyle factors

\section{Measurement of explanatory variables}

We measured lung function and undertook skin prick tests to common aeroallergens to investigate whether the presence of respiratory obstruction or allergic sensitisation could help explain any possible associations uncovered.

Lung function tests. Lung function testing was performed in schools by trained members of the research team. All spirometric measurements were taken in a sitting position using a Vitalograph Pneumotrac spirometer (Vitalograph, Buckingham, UK). England The best of at least three technically acceptable values for forced expiratory volume in $1 \mathrm{~s}\left(\mathrm{FEV}_{1}\right)$, forced vital capacity (FVC), (FEV F $_{1} \% \mathrm{FEV}_{1} / \mathrm{FVC}$ ratio and peak expiratory flow were selected. $^{43-45}$

Skin prick tests. Skin prick tests were undertaken using the volar aspect of the forearm, the skin having first been marked with a pen. Thereafter, one drop of each solution to be tested was put on the skin beside the respective mark. A panel of eight allergens (i.e., cat, Dermatophagoides farinae, Dermatophagoides pteronyssinus, grass mix, Rye, tree mix (early blossoming), tree mix (mid-blossoming) and weed mix) were used. Histamine $10 \mathrm{mg} / \mathrm{ml}$ and $50 \%$ glycerine were used as positive and negative controls, respectively. The size of the weal was recorded as the mean of the greatest diameter and the diameter perpendicular to its midpoint. Recordings were taken after $15 \mathrm{~min}$ and a mean diameter of $3 \mathrm{~mm}$ or greater than the negative control was regarded as positive. ${ }^{46}$

\section{Statistical methods}

All statistical analyses were carried out using Statistical Package for Social Sciences (SPSS, Chicago, IL, USA), version 16.0, for Windows and Confidence Interval Analysis (CIA) software (University of Southampton, Southampton, UK) ${ }^{47}$ All analyses were undertaken separately for boys and girls because the literature suggested that we might find differing degrees of association between obesity and asthma. ${ }^{21,28}$ Univariate comparisons between the matched cases and controls were carried out by paired $t$-test variables and Wilson's method for binary variables. The differences in measures of obesity between the matched pairs of children were tested for variation between schools, separately for each sex, by one-way analysis of variance. There were no significant differences between schools in any of the four measures, suggesting no important cluster effects, and all further analyses were therefore carried out without any adjustment for school effects. Multiple conditional logistic regression was used to investigate the relationship between asthma and explanatory variables, adjusted for confounders. In the regression models, only those variables that differed significantly between cases and controls were included as covariates.

\section{Sample size calculations}

Our preliminary work ${ }^{30}$ suggested that the prevalence of asthma was around $15 \%$ and therefore a sample of around 5,000 children needed to be recruited into the cross-sectional study in order to recruit sufficient numbers of cases $(\geqslant 600)$ to give $80 \%$ power to detect a mean difference of around 0.4 in BMI between cases and the same number of controls based on a s.d. of three units for BMI. 


\section{RESULTS}

Recruitment of schools

All 37 schools that were approached agreed to participate.

Characteristics of cases and controls

Data were collected on 388 matched pairs of boys and 244 matched pairs of girls. Table 1 summarises the main characteristics of cases and controls among boys and girls. The demographic and lifestyle variables that differed between cases and controls in males were birth weight, smoking habits of the father, breastfeeding, taking of paracetamol and antibiotics during the first year of life, taking of paracetamol in the previous 12 months and the frequency of trucks passing near the home. In girls, demographic and lifestyle variables that differed between cases and controls were smoking habits of the father, breastfeeding, exposure to farm animals during the first year of life, taking paracetamol during the previous 12 months, exposure to a cat during the previous 12 months, the type of air conditioning system at home and meat and nut consumption.

\section{Univariate analysis}

Table 2 shows the unadjusted effect of each of the obesity measures on the risk of having asthma in boys and girls. All four obesity measures (BMI, weight, TSFT and WC) were found to be positively associated with asthma in both boys and girls. The odds ratios in girls were consistently higher than those in boys.

Table 1. Descriptive comparisons between cases and controls in male and female children: figures shown for cases and controls are mean (s.d.) or number (\%)

\begin{tabular}{|c|c|c|c|c|c|c|}
\hline \multirow[t]{2}{*}{ Variables } & \multicolumn{3}{|c|}{ Males } & \multicolumn{3}{|c|}{ Females } \\
\hline & Cases $(\mathrm{n}=388)$ & $\begin{array}{l}\text { Controls } \\
(\mathrm{n}=388)\end{array}$ & $\begin{array}{l}\text { Differences for the mean or for } \\
\text { rates between cases and } \\
\text { controls }(95 \% \mathrm{Cl})\end{array}$ & Cases $(n=244)$ & $\begin{array}{l}\text { Controls } \\
(\mathrm{n}=244)\end{array}$ & $\begin{array}{l}\text { Differences for the mean or for } \\
\text { rates between cases } \\
\text { and controls }(95 \% \mathrm{Cl})\end{array}$ \\
\hline \multicolumn{7}{|l|}{ Measures of obesity } \\
\hline \multicolumn{7}{|l|}{ Primary measures mean (s.d.) } \\
\hline BMI $\left(\mathrm{kg} / \mathrm{m}^{2}\right)$ & $17.0(3.8)$ & $15.8(2.5)$ & $1.2(+0.7,+1.7)^{\mathrm{a}}$ & $19.0(4.4)$ & $15.9(2.1)$ & $3.1(+2.5,+3.7)^{\mathrm{a}}$ \\
\hline \multicolumn{7}{|l|}{ Secondary measures mean (s.d.) } \\
\hline TSFT $(\mathrm{mm})$ & $10.5(4.2)$ & $9.2(3.3)$ & $1.3(+0.8,+1.8)^{\mathrm{a}}$ & $13.8(5.3)$ & $10.5(3.2)$ & $3.3(+2.6,+4.1)^{\mathrm{a}}$ \\
\hline WC $(\mathrm{cm})$ & $56.6(8.8)$ & $53.6(6.4)$ & $3(+1.9,+4.0)^{a}$ & $61.0(10.1)$ & $53.9(5.8)$ & $7.1(+5.6,+8.4)^{\mathrm{a}}$ \\
\hline Weight (kg) & $26.1(8.0)$ & $23.9(5.7)$ & $2.2(+1.2,+3.2)^{\mathrm{a}}$ & $30.4(9.6)$ & $24.1(5.4)$ & $6.3(+4.92,+7.69)^{\mathrm{a}}$ \\
\hline \multicolumn{7}{|l|}{ Explanatory variables } \\
\hline \multicolumn{7}{|l|}{$\begin{array}{l}\text { Lung function measures } \\
\text { L }\end{array}$} \\
\hline FVC (Lt) mean (s.d.) & $1.35(0.36)$ & $1.46(0.37)$ & $-0.11(-0.16,-0.06)^{\mathrm{a}}$ & $1.17(0.31)$ & $1.22(0.30)$ & $-0.05(-0.10,+0.00)$ \\
\hline $\mathrm{FEV}_{1}(\mathrm{Lt})$ mean (s.d.) & $1.15(0.30)$ & $1.31(0.34)$ & $-0.16(-0.21,-0.12)^{\mathrm{a}}$ & $0.96(0.27)$ & $1.08(0.28)$ & $-0.12(-0.17,-0.08)^{\mathrm{a}}$ \\
\hline PEFR (Lt) mean (s.d.) & $2.40(0.64)$ & $2.72(0.56)$ & $-0.32(-0.41,-0.24)^{\mathrm{a}}$ & $1.77(0.76)$ & $2.36(0.57)$ & $-0.59(-0.70,-0.47)^{\mathrm{a}}$ \\
\hline \multicolumn{7}{|c|}{ Sensitisation to one or more allergens $(\geqslant 3 \mathrm{~mm}), n(\%)$} \\
\hline Cat & $216(56)$ & $55(14)$ & $42(+36.0,+48.0)^{a}$ & $166(68)$ & $35(14)$ & $54(+46.7,+61.3)^{a}$ \\
\hline Dermatophagoides farinae & $99(25)$ & $21(5)$ & $20(+15.2,+24.8)^{\mathrm{a}}$ & $79(32)$ & $6(2)$ & $30(+23.9,+36.1)^{a}$ \\
\hline $\begin{array}{l}\text { Dermatophagoides } \\
\text { pteronyssinus }\end{array}$ & $99(25)$ & $11(3)$ & $22(+17.4,+26.6)^{a}$ & $91(37)$ & $16(6)$ & $31(+24.3,+37.8)^{a}$ \\
\hline Grass mix & $66(17)$ & $14(4)$ & $13(+8.8,+17.2)^{\mathrm{a}}$ & $51(21)$ & $5(2)$ & $19(+13.6,+24.4)^{\mathrm{a}}$ \\
\hline Rye & $55(14)$ & $15(4)$ & $10(+6.0,+14.0)^{\mathrm{a}}$ & $83(34)$ & $2(1)$ & $33(+26.9,+39.1)^{\mathrm{a}}$ \\
\hline Tree mix (early blossoming) & $70(18)$ & $13(3)$ & $15(+10.8,+19.2)^{\mathrm{a}}$ & 89 (36) & $4(2)$ & $32(+27.7,+40.3)^{\mathrm{a}}$ \\
\hline Tree mix (mid-blossoming) & $80(21)$ & $18(5)$ & $16(+11.4,+20.6)^{\mathrm{a}}$ & $81(33)$ & $3(1)$ & $30(+26.0+38.0)^{a}$ \\
\hline Weed mix & $62(16)$ & $10(3)$ & $13(+9.0,+17.0)^{\mathrm{a}}$ & $66(27)$ & $7(2)$ & $20(+19.2,+30.8)^{\mathrm{a}}$ \\
\hline Sensitisation to $1 \geqslant$ allergen & $325(84)$ & $107(27)$ & $57(+51.3,+62.7)^{\mathrm{a}}$ & $234(96)$ & $54(22)$ & $74(+68.2,+79.8)^{\mathrm{a}}$ \\
\hline \multicolumn{7}{|l|}{ Potential confounders } \\
\hline $\begin{array}{l}\text { Father's age (years) } \\
\text { mean (s.d.) }\end{array}$ & $43.3(8.4)$ & $42.1(7.8)$ & $1.12(-0.04,+2.28)$ & $44.1(9.0)$ & $44.8(8.9)$ & $0.1(-5.0,+5.2)$ \\
\hline Mother's age (years) mean (s.d.) & $35(6.1)$ & $34.6(6.2)$ & $0.36(-0.51,+1.23)$ & $36.2(6.0)$ & $36.1(6.1)$ & $-0.1(-4.3,+4.1)$ \\
\hline Birth weight $(\mathrm{kg})$ mean (s.d.) & $2.90(0.66)$ & $3.00(0.58)$ & $-0.10(-0.20,-0.01)^{\mathrm{a}}$ & $2.94(0.67)$ & $2.83(0.62)$ & $0.11(-0.02,+0.24)$ \\
\hline \multicolumn{7}{|c|}{ Father's education (highest qualification), $n(\%)$} \\
\hline None & $14(3.7)$ & $21(5.6)$ & $-1.9(-4.9,+1.1)$ & $22(9.4)$ & $14(5.9)$ & $3.5(-1.2,+8.2)$ \\
\hline General education & $192(50.8)$ & $198(53.2)$ & $-2.4(-1.0,+4.0)$ & $132(56.2)$ & $156(65.3)$ & $-9.1(-8.9,+8.7)$ \\
\hline Higher education & $172(45.5)$ & $153(41.1)$ & $4.4(-3.0,+11.0)$ & $81(34.5)$ & $69(28.9)$ & $5.6(-2.6,+13.6)$ \\
\hline \multicolumn{7}{|c|}{ Mother's education (highest qualification), $n$ (\%) } \\
\hline None & $14(3.7)$ & $32(8.3)$ & $-4.6(-7.9,-1.3)^{\mathrm{a}}$ & $26(10.9)$ & $29(12.0)$ & $-1.1(-6.7,+4.5)$ \\
\hline General education & $208(54.5)$ & $205(53.4)$ & $1.1(-5.9,+8.1)$ & $141(59.0)$ & $144(59.8)$ & $-0.8(-9.5,+7.9)$ \\
\hline Higher education & 160 (41.9) & $147(38.3)$ & $3.6(-3.3,+10.5)$ & $72(30.1)$ & $68(28.2)$ & $1.9(-6.2,+10)$ \\
\hline \multicolumn{7}{|l|}{ Father smoker, $n(\%)$} \\
\hline Yes & $129(33.3)$ & $96(24.8)$ & $8.5(+2.1,+14.9)^{\mathrm{a}}$ & $56(23.1)$ & $77(31.8)$ & $-8.7(-16.6,-0.8)^{\mathrm{a}}$ \\
\hline No & $258(66.7)$ & $291(75.2)$ & $-8.5(-14.9,-2.1)^{\mathrm{a}}$ & $186(76.9)$ & $168(68.2)$ & $8.7(+0.8,+16.6)^{a}$ \\
\hline \multicolumn{7}{|l|}{ Mother smoker, $n$ (\%) } \\
\hline Yes & $5(1.3)$ & $1(0.3)$ & $1.0(-0.25,+2.25)$ & $4(1.7)$ & $2(0.8)$ & $0.9(-1.1,+2.9)$ \\
\hline No & $382(98.7)$ & $385(99.7)$ & $-1.0(-2.3,+0.3)$ & $236(98.3)$ & $241(99.2)$ & $-0.9(-2.9,+1.1)$ \\
\hline \multicolumn{7}{|l|}{ Birth order, $n(\%)$} \\
\hline First child & $206(53.4)$ & $206(53.1)$ & $0.3(-6.7,+7.3)$ & $43(17.8)$ & $47(19.5)$ & $-1.7(-8.6,+5.2)$ \\
\hline Second child & $125(32.4)$ & $123(31.7)$ & $0.7(-5.9+7.3)$ & $189(78.1)$ & $180(74.7)$ & $3.4(-4.1,+10.9)$ \\
\hline Third or greater & $55(14.2)$ & $56(15.2)$ & $-1.0(-6.0,+4.0)$ & $10(4.1)$ & $14(5.8)$ & $-1.7(-5.5,+2.1)$ \\
\hline \multicolumn{7}{|c|}{ Was the child born in Madinah?, $n(\%)$} \\
\hline Yes & $332(85.8)$ & $328(85.4)$ & $0.4(-4.5,+5.3)$ & $202(84.5)$ & $200(82.6)$ & $1.9(-4.7,+8.5)$ \\
\hline No & $55(14.2)$ & $56(14.6)$ & $-0.4(-5.3,+4.5)$ & $37(15.5)$ & $42(17.4)$ & $-1.9(-8.5,+4.7)$ \\
\hline \multicolumn{7}{|l|}{ Did the mother breastfeed?, $n(\%)$} \\
\hline Yes & $290(75.9)$ & $330(85.5)$ & $-9.6(-15.1,-4.1)^{a}$ & $208(86.7)$ & $193(80.1)$ & $6.6(0.0,+13.0)$ \\
\hline No & $92(24.1)$ & $56(14.5)$ & $8.5(+2.1,+14.9)^{\mathrm{a}}$ & $32(13.3)$ & $48(19.9)$ & $-8.7(-16.6,-0.8)^{a}$ \\
\hline \multicolumn{7}{|c|}{ Medication given in the 1 st year of child's life, $n(\%)$} \\
\hline Paracetamol & 367 (95.6) & $329(88.4)$ & $7.2(+3.4,+11.0)^{\mathrm{a}}$ & $213(89.9)$ & 209 (87.4) & $2.5(-3.1,+8.1)$ \\
\hline Antibiotics & $311(82.3)$ & $213(57.9)$ & $24.4(+18.2,+30.6)^{\mathrm{a}}$ & $164(69.5)$ & $148(61.7)$ & $7.8(-0.6,+16.2)$ \\
\hline
\end{tabular}


Table. 1. (Continued)

\begin{tabular}{|c|c|c|c|c|c|c|}
\hline \multirow[t]{2}{*}{ Variables } & \multicolumn{3}{|c|}{ Males } & \multicolumn{3}{|c|}{ Females } \\
\hline & Cases $(n=388)$ & $\begin{array}{l}\text { Controls } \\
(\mathrm{n}=388)\end{array}$ & $\begin{array}{l}\text { Differences for the mean or for } \\
\text { rates between cases and } \\
\text { controls }(95 \% \text { CI) }\end{array}$ & Cases $(n=244)$ & $\begin{array}{l}\text { Controls } \\
(\mathrm{n}=244)\end{array}$ & $\begin{array}{c}\text { Differences for the mean or for } \\
\text { rates between cases } \\
\text { and controls }(95 \% \mathrm{Cl})\end{array}$ \\
\hline \multicolumn{7}{|c|}{ Paracetamol administered in the last 12 months, $n(\%)$} \\
\hline Once a week at least & $87(22.9)$ & 70 (18.9) & $4.0(-1.7,+9.7)$ & $54(22.9)$ & 39 (16.9) & $6.0(-1.1,+13.1)$ \\
\hline Once a month at least & $220(57.9)$ & $195(52.7)$ & $5.2(-1.8,+12.2)$ & $135(57.2)$ & $125(54.1)$ & $3.1(-5.7,+11.9)$ \\
\hline Once a year at least & $73(19.2)$ & 105 (28.4) & $-9.2(-15.2,-3.2)^{\mathrm{a}}$ & $47(19.9)$ & $67(29.0)$ & $-9.1(-16.7,-1.5)^{\mathrm{a}}$ \\
\hline \multicolumn{7}{|l|}{ Exposure to animals, $n(\%)$} \\
\hline $\begin{array}{l}\text { Farm animal when mother } \\
\text { was pregnant }\end{array}$ & $11(2.9)$ & $11(2.9)$ & $0.0(-2.4,+2.4)$ & $14(6.1)$ & $8(3.4)$ & $2.7(-1.1,+6.5)$ \\
\hline $\begin{array}{l}\text { Cat at home in the } 1 \text { st year } \\
\text { of child's life }\end{array}$ & $15(3.9)$ & $15(3.9)$ & $0.0(-2.7,+2.7)$ & $19(7.9)$ & $6(2.5)$ & $5.4(+1.5,+9.3)^{\mathrm{a}}$ \\
\hline $\begin{array}{l}\text { Cat at home in the last } \\
12 \text { months }\end{array}$ & $29(7.5)$ & $25(6.5)$ & $1.0(-2.6,+4.6)$ & $18(7.5)$ & $12(5.0)$ & $2.5(+1.2,+8.8)^{\mathrm{a}}$ \\
\hline $\begin{array}{l}\text { Farm animal in the 1st year } \\
\text { of child life }\end{array}$ & $24(6.2)$ & $16(4.2)$ & $2.0(-1.1,+5.1)$ & $16(6.8)$ & $5(2.1)$ & $4.7(+1.1,+8.3)^{\mathrm{a}}$ \\
\hline \multicolumn{7}{|l|}{ Taking exercise per week, $n(\%)$} \\
\hline Never & $241(64.3)$ & $254(68.8)$ & $-4.5(-11.1,+2.1)$ & $201(85.5)$ & $200(86.2)$ & $-0.7(-6.9,+5.5)$ \\
\hline Once or twice a week & $101(26.9)$ & $86(23.3)$ & $3.6(-2.5,+9.7)$ & $31(13.2)$ & $25(10.8)$ & $2.4(-3.4,+8.2)$ \\
\hline Three or more a week & $33(8.8)$ & $29(7.9)$ & $0.9(-3.0,+4.8)$ & $3(1.3)$ & $7(3.0)$ & $-1.7(-4.3,+0.9)$ \\
\hline \multicolumn{7}{|l|}{ Watching TV, $n$ (\%) } \\
\hline$<3 \mathrm{~h}$ per day & $228(60.0)$ & $241(64.6)$ & $-4.6(-11.4,+2.2)$ & $137(56.8)$ & $128(54.9)$ & $1.9(-6.9,+10.7)$ \\
\hline$>3 \mathrm{~h}$ per day & $152(40.0)$ & $132(35.4)$ & $4.6(-2.2,+11.4)$ & $104(43.2)$ & $105(45.1)$ & $-1.9(-10.7,+6.9)$ \\
\hline \multicolumn{7}{|c|}{ What is the fuel normally used in cooking in your household?, $n(\%)$} \\
\hline Electricity only & $20(5.2)$ & $20(5.2)$ & $0(-3.1,+3.1)$ & $9(3.8)$ & $15(6.3)$ & $-2.5(-6.4,+1.4)$ \\
\hline Gas only & $351(90.9)$ & $349(90.4)$ & $0.5(-3.6,+4.6)$ & $223(92.9)$ & $220(92.4)$ & $0.5(-4.1,+5.1)$ \\
\hline Both electricity \& gas & $15(3.9)$ & $17(4.4)$ & $-0.5(-3.3,+2.3)$ & $8(3.3)$ & $3(1.3)$ & $2.0(-0.7,+4.7)$ \\
\hline \multicolumn{7}{|l|}{ Air conditioning type, $n(\%)$} \\
\hline Electric fan only & $3(0.8)$ & $1(0.3)$ & $0.5(-0.54,+1.54)$ & $1(0.4)$ & $2(0.8)$ & $-0.4(-1.77,+0.97)$ \\
\hline Water system only & $4(1.0)$ & $5(1.3)$ & $-0.3(-1.8,+1.2)$ & $4(1.7)$ & $10(4.1)$ & $-2.4(-5.4,+0.6)$ \\
\hline Freon system only & $365(94.3)$ & 372 (96.6) & $-2.3(-5.2,+0.6)$ & $194(82.2)$ & $223(92.5)$ & $-10.3(-16.1,-4.5)^{\mathrm{a}}$ \\
\hline Both Freon \& water systems & $15(3.9)$ & $7(1.8)$ & $2.1(-0.2,+4.4)$ & 37 (15.7) & $6(2.5)$ & $13.2(+8.2,+18.2)^{\mathrm{a}}$ \\
\hline \multicolumn{7}{|c|}{ How often does a truck pass through the street adjacent to your home?, $n(\%)$} \\
\hline Rarely & $237(61.6)$ & $268(70.9)$ & $-9.3(-15.9,-2.7)^{\mathrm{a}}$ & $168(70.3)$ & $169(70.7)$ & $-0.4(-8.5,+7.7)$ \\
\hline Frequently & $148(38.4)$ & $110(29.1)$ & $9.3(+2.7,+15.9)^{\mathrm{a}}$ & $71(29.7)$ & $70(29.3)$ & $0.4(-7.7,+8.5)$ \\
\hline \multicolumn{7}{|c|}{ Diet-How many times a week does your child eat the following?, $n(\%)$} \\
\hline \multicolumn{7}{|l|}{ Meats } \\
\hline Never & $20(5.2)$ & $16(4.2)$ & $1.0(-4.0,+2.0)$ & $9(3.7)$ & $26(10.9)$ & $-7.2(-11.8,-2.6)^{\mathrm{a}}$ \\
\hline Once or twice a week & $110(28.6)$ & $122(31.8)$ & $-3.2(-9.7,+3.3)$ & $83(34.2)$ & 81 (33.9) & $0.3(-8.1,+8.7)$ \\
\hline Three or more a week & $254(66.1)$ & $246(64.1)$ & $2.0(-4.7,+8.7)$ & $151(62.1)$ & $132(55.2)$ & $6.9(-1.8,+15.6)$ \\
\hline \multicolumn{7}{|l|}{ Fruits } \\
\hline Never & $68(17.7)$ & $44(11.5)$ & $6.2(-6.9,+19.3)$ & $29(12.0)$ & $24(10.0)$ & $2.0(-3.5,+7.5)$ \\
\hline Once or twice a week & $167(43.4)$ & $175(45.9)$ & $-2.5(-9.5,+4.5)$ & $114(47.1)$ & $115(48.1)$ & $-1.0(-9.9,+7.9)$ \\
\hline Three or more a week & $150(39.0)$ & $162(42.5)$ & $-3.5(-10.4,+3.4)$ & 99 (40.9) & $100(41.8)$ & $-0.9(-9.6,+7.8)$ \\
\hline \multicolumn{7}{|l|}{ Rice } \\
\hline Never & $9(2.4)$ & $8(2.1)$ & $0.3(-1.8,+2.4)$ & $6(2.5)$ & $10(4.2)$ & $-1.7(-4.9,+1.5)$ \\
\hline Once or twice a week & $70(18.4)$ & $83(21.7)$ & $-3.3(-8.9,+2.3)$ & $45(19.0)$ & 47 (19.7) & $-0.7(-7.7,+6.3)$ \\
\hline Three or more a week & 301 (79.2) & 291 (76.2) & $3.0(-2.9,+8.9)$ & $186(78.2)$ & $182(76.2)$ & $2.0(-5.4,+9.4)$ \\
\hline \multicolumn{7}{|l|}{ Nuts } \\
\hline Never & $224(59.4)$ & $227(60.7)$ & $-1.3(-8.2,+5.6)$ & $151(62.9)$ & $116(50.0)$ & $12.9(+4.2,+21.6)^{\mathrm{a}}$ \\
\hline Once or twice a week & $134(35.5)$ & 118 (31.6) & $3.9(-2.7,+10.5)$ & $73(30.4)$ & $93(40.1)$ & $-9.7(-18.1,-1.3)^{a}$ \\
\hline Three or more a week & $19(5.0)$ & $29(7.8)$ & $-2.8(-6.2,+0.6)$ & $16(6.7)$ & $23(9.9)$ & $-3.2(-8.1,+1.7)$ \\
\hline \multicolumn{7}{|l|}{ Fast food } \\
\hline Never & $217(56.7)$ & $225(59.2)$ & $-2.5(-9.4,+4.4)$ & $160(67.5)$ & $164(69.8)$ & $-2.3(-10.5,+5.9)$ \\
\hline Once or twice a week & $132(34.5)$ & $122(32.1)$ & $2.4(-4.2,+9.0)$ & $60(25.3)$ & $56(23.8)$ & $1.5(-6.1,+9.1)$ \\
\hline Three or more a week & $34(8.9)$ & $33(8.7)$ & $0.2(-3.8,+4.2)$ & $17(7.2)$ & $15(6.4)$ & $0.8(-3.7,+5.3)$ \\
\hline
\end{tabular}

Note: Missing data for individual variables are not shown.

Abbreviations: BMI, body mass index; $\mathrm{Cl}$, confidence interval; TSFT, triceps skin fold thickness; WC, waist circumference.

${ }^{a}$ Statistically significant difference between cases and controls.

Multivariate analysis

Table 3 shows the effect of BMI on the risk of asthma in boys and girls, adjusted for relevant potential confounding sociodemographic and lifestyle variables. Only those variables showing univariate associations with asthma were included in each model. These analyses showed that BMI was still strongly associated with asthma after adjustment for these covariates in both boys and girls. The adjusted odds ratio was higher in girls than in boys.

Investigation of possible causal pathways

There was-in both sexes-strong evidence that children with asthma had greater respiratory obstruction and were more sensitised to aeroallergens in comparison with those with no history of asthma. Table 4 shows the impact of factoring measures of respiratory obstruction and this reveals a negligible impact on the associations between BMI and asthma in boys and girls.
Table 2. Unadjusted effect of obesity and adiposity measures (TSFT, WC and weight) on the odds of asthma in males and females

\begin{tabular}{lcc}
\hline Measures of obesity and adiposity & $\begin{array}{c}\text { Multiplicative increase in odds of having } \\
\text { asthma }(95 \% \mathrm{Cl} \text { per unit increase of the } \\
\text { independent variable }\end{array}$ \\
\cline { 2 - 2 } & \multicolumn{1}{c}{ Males } & Females \\
\hline $\begin{array}{l}\text { Obesity measure } \\
\text { BMI }\left(\mathrm{kg} / \mathrm{m}^{2}\right)\end{array}$ & $1.14(1.08,1.20)$ & $1.37(1.26,1.50)$ \\
Adiposity measures & & \\
TSFT (mm) \\
$\begin{array}{l}\text { WC }(\mathrm{cm}) \\
\text { Weight }(\mathrm{kg})\end{array}$ & $1.10(1.06,1.15)$ & $1.24(1.16,1.33)$ \\
\hline
\end{tabular}

Abbreviations: $\mathrm{BMI}$, body mass index; $\mathrm{Cl}$, confidence interval; TSFT, triceps skin fold thickness; WC, waist circumference. 
Table 3. Adjusted ORs $(95 \% \mathrm{Cl})$ for the association between $\mathrm{BMI}$ on asthma in males and females

Independent $(X)$ variables in the multiple logistic regression model ${ }^{a}$

ORs of developing asthma (95\% Cl) adjusted for other factors

BMI

Birth weight

Mother education (none compared with higher)

Mother education (general compared with higher)

Father smoking

Breastfed

Paracetamol given in the 1st year of child's life

Antibiotics given in the 1st year of child's life

Paracetamol given to the child in the last 12 months (once a week compared with yearly)

Paracetamol given to the child in the last 12 months (once a month compared with yearly)

Cat at home in the 1st year of child's life

Cat at home in the last 12 months

Farm animal in the 1st year of child's life

Air conditioning type used at home (electric fan compared with Freon system)

Air conditioning type used at home (water system compared with Freon system)

Air conditioning type used at home (both Freon and water system compared

with Freon system)

Frequency of a truck passing through the street adjacent to the home (frequently

compared with rarely)

Eating meat (once or twice a week compared with never)

Eating meat (three times a week or more compared with never)

Eating nuts (once or twice a week compared with never)

Eating nuts (three times a week or more compared with never)

\begin{tabular}{cc}
\hline Males & Females \\
\hline $1.11(1.03,1.19)$ & $1.38(1.23,1.56)$ \\
$0.71(0.49,1.02)$ & $\mathrm{b}$ \\
$0.48(0.16,1.44)$ & $\mathrm{b}$ \\
$0.82(0.51,1.32)$ & $0.45(0.22,0.93)$ \\
$1.17(0.76,1.80)$ & $3.62(1.42,9.25)$ \\
$0.74(0.44,1.26)$ & $\mathrm{b}$ \\
$1.66(0.67,4.09)$ & $\mathrm{b}$ \\
$2.45(1.54,3.91)$ & $7.09(2.48,20.8)$ \\
$1.94(1.00,3.80)$ & $2.23(1.05,4.72)$ \\
$1.90(1.14,3.14)$ & $0.83(0.10,7.28)$ \\
$\mathrm{c}$ & $2.25(0.42,12.1)$ \\
$\mathrm{c}$ & $2.56(0.36,18.4)$ \\
$\mathrm{c}$ & $3.58(0.02,529)$ \\
$\mathrm{c}$ & $0.51(0.09,2.96)$ \\
$\mathrm{c}$ & $19.4(3.56,106)$ \\
$\mathrm{c}$ &
\end{tabular}

$1.39(0.89,2.78)$

b

$10.2(2.03,51.2)$

$8.68(1.83,41.0)$

$0.55(0.29,1.04)$

$0.80(0.27,2.37)$

Abbreviations: $\mathrm{BMI}$, body mass index; $\mathrm{Cl}$, confidence interval; OR, odds ratio.

${ }^{a}$ Only those variables that remained in the model in the last step of the backward stepwise regression process are displayed in the table.

${ }^{\mathrm{b}} \mathrm{Not}$ in the model for females.

${ }^{c}$ Not in the model for males.

Table 4. Estimates $(95 \% \mathrm{Cls})$ for the coefficient of $\mathrm{BMI}$ in conditional logistic regression analysis adjusted for selected lung function and sensitisation and also for other factors found to be associated with obesity in Table 1

\begin{tabular}{lcc}
\hline Lung and sensitisation factors & Males & Females \\
\hline None & $1.11(1.03,1.19)$ & $1.38(1.23,1.56)$ \\
FEV $_{1}$ & $1.10(1.02,1.18)$ & $1.37(1.22,1.54)$ \\
FVC & $1.11(1.03,1.19)$ & $1.40(1.24,1.57)$ \\
Sensitisation to more than & $1.09(0.99,1.19)$ & $1.25(0.96,1.60)$ \\
one allergen & & \\
FEV ${ }_{1}+$ sensitisation to more & $1.09(0.98,1.19)$ & $1.28(0.96,1.69)$ \\
than one allergen & $1.09(0.99,1.19)$ & $1.25(0.97,1.61)$ \\
FVC+sensitisation to more & & \\
than one allergen & & \\
\hline
\end{tabular}

Abbreviations: $\mathrm{BMI}$, body mass index; $\mathrm{Cl}$, confidence interval; $\mathrm{FEV}_{1}$, forced expiratory volume in $1 \mathrm{~s}$; FVC, forced vital capacity.

Table 4 also reveals the impact of factoring the presence of allergic sensitisation into the analysis and this in contrast shows a more marked reduction in the associations in girls, although a more modest impact in boys.

\section{DISCUSSION}

Main findings

This large case-control study has demonstrated consistent associations between measures of overall, central and peripheral obesity, and asthma in boys and girls. In keeping with previous work, ${ }^{17,20}$ we found a stronger association in girls than in boys, but unlike other studies we observed this difference in the context of studying pre-pubertal children. Focusing on BMI, we then demonstrated that this association was still present after adjusting for a wide range of potential demographic and lifestylerelated confounding factors. In an attempt to investigate whether respiratory obstruction and/or allergic sensitisation may lie on the causal pathway between obesity and asthma, ${ }^{11,26}$ we adjusted separately and then combined for their effects and found that respiratory obstruction had only a very modest impact, but that the association was more attenuated when adjusting for sensitisation, particularly in girls. Adjusting simultaneously for both lung function and sensitisation did not further attenuate the relationship, suggesting that respiratory obstruction is unlikely to be an important mechanism but that obesity may at least partially exert its effects by increasing the risk of allergic sensitisation. Overall, this study therefore adds to the increasing body of evidence implicating obesity as a risk factor for the development of asthma showing that this relationship also holds true in a population of Middle Eastern origin and provides important pointers into how this relationship may or may not be mediated in this population.

\section{Strengths and limitations of this study}

Key strengths of this work include the fact that we conducted a large, adequately powered, investigation, our use of a validated and extensively used questionnaire to identify cases and controls, careful measurements of a range of measures of obesity ${ }^{17}$ by trained personnel who were blinded to case status the measurement of, and adjustments for, a range of potential confounders and the a priori decision to undertake separate analyses in boys and girls. ${ }^{21,28}$ In addition, we sought to extend previous work by investigating two important possible causal mechanisms. 
The main limitations of this work are those inherent in case-control studies-namely the risk of residual confounding, recall bias and an inability to establish a temporal relationship between the onset of obesity and the subsequent development of asthma; reverse causality therefore remains a possibility. Moreover, the identification of cases was based on responses to the ISAAC questionnaire and this may have been affected by parental behaviours and diagnostic bias; although a validated culturally appropriate questionnaire was used, there remains therefore the possibility of misclassification errors. If present, this is likely to have been operating in a non-differential manner, which would have resulted in blunting the associations between obesity and asthma rather than creating spurious associations. Future work should seek to build on this by using more objective assessments to diagnose asthma, although given the numbers of subjects who need to be studied this may well prove financially and logistically challenging.

Interpretation of findings in relation to previously published research

Our study is consistent with an increasing number of epidemiological studies that have reported a positive association between obesity and the risk of developing childhood asthma. ${ }^{17,20}$ As with other investigators, ${ }^{17}$ we have found that this association was stronger in girls. Whether this sex difference is simply due to the higher levels of obesity observed in female cases (Table 1) or due to difference in body fat distribution-particularly centrally, where it is believed to exert the greatest inflammatory effect, ${ }^{48,49}$ as reflected by the larger WC and prevalence of sensitisation in females with asthma (Table 1) - and/or associated biochemical responses is unclear. ${ }^{48,49}$ The fact that sensitisation was a strong risk factor for asthma confirms the findings of a number of previous epidemiological investigations. ${ }^{46}$

There is a limited body of evidence investigating the relationship between obesity and allergic sensitisation, and the available evidence has been noted to be inconsistent and inconclusive. ${ }^{21}$ A large and important recent Swedish birth cohort study found that increased BMI at age 7 was associated with an increased risk of allergic sensitisation to aeroallergens and the development of childhood asthma, but that asthma risk was not increased if the increased BMI was confined to the first 4 years of life. ${ }^{50}$ It is thus likely that any possible relationship between obesity and allergic sensitisation is strongly influenced by age. Sex is also important as recent work has also demonstrated that levels of the adipocytederived hormone leptin are closely correlated with BMI in early life, and that leptin levels tend to be higher in girls than in boys, ${ }^{51}$ which may explain why a stronger and more consistent relationship is observed between BMI and asthma in girls. ${ }^{21}$ Future work should now aim to study carefully characterised populations and also progress mechanistic lines of enquiry through measurement of key biomarkers including the adipokines adiponectin and leptin, other obesity-related hormones such as insulin and neuropepeides, and the pro-inflammatory cytokines tumour necrosis factor, interleukin-6 and interleukin- $1 \mathrm{~B}^{27}$ it is also important to investigate whether obesity reduces immunological tolerance through downregulation of interleukin-10 secretion and study the combined impact of these changes on regulatory T lymphocytes (Tregs). ${ }^{52}$

\section{Implications for future research, policy and practice}

The findings of the present study may be valuable for public health authorities as it provides additional evidence of the considerable adverse risks associated with obesity. Although causality cannot be proven by this or indeed any other epidemiological investigation, the findings from this work, when combined with an increasing number of studies worldwide, ${ }^{12,13,17,20}$ provide increasing evidence of a causal relationship between obesity and asthma. This then adds weight to the argument to consider and investigate the role of interventions to prevent/tackle obesity early on in life and thereby possibly reduce the risk of developing asthma. Even if such causality has not been unequivocally proven, public health authorities should consider applying the 'precautionary principle $^{153}$ and undertake initiatives for reducing obesity among children. Reduction of obesity in children will offer benefits in the general health status, as childhood obesity is a well-established risk factor for several other diseases. ${ }^{54}$ Moreover, given the high prevalence of obesity and asthma, school health departments should consider focussing attention on establishing systems for monitoring obesity and asthma among schoolchildren.

\section{CONCLUSIONS}

In conclusion, our large matched case-control study provides the first evidence demonstrating an association between obesity and asthma in pre-pubertal male and female Saudi children. Our investigation of key causal pathways suggests that this relationship may indeed be causal, being at least partially mediated through the pro-inflammatory effects of central obesity, which increase the risk of allergic sensitisation to aeroallergens. This work has also demonstrated that mechanical obstruction is unlikely to be an important aetiological mechanism in overweight, pre-pubertal children.

\section{ACKNOWLEDGEMENTS}

We thank the General Directorate of Education in Madinah region, the General Directorate of School Health in the Ministry of Education in Riyadh (both boys and girls sections), the research team, and all staff in the participating schools. We also thank the parents and children who participated in this study.

\section{CONTRIBUTIONS}

AS, MN, RB and CA were involved in conceiving and designing this study. MN undertook the field work under the supervision of AS and analysed the data under the supervision of RE. MN and AS led the drafting of the manuscript and $\mathrm{RB}, \mathrm{CA}$ and RE commented on drafts of the manuscript.

\section{COMPETING INTERESTS}

AS is joint Editor-in-Chief of npjPCRM, but was not involved in the editorial review of, nor the decision to publish, this article. None of the other authors report any conflict of interest.

\section{FUNDING}

This study was supported by the Saudi Arabian Ministry of Higher Education Scholarship. AS is supported by The Commonwealth Fund, a private independent foundation based in New York City. The views presented here are those of the author and not necessarily those of The Commonwealth Fund, its directors, officers or staff.

\section{REFERENCES}

1 Bereket A, Kiess W, Lustig RH, Muller HL, Goldstone AP, Weiss R et al. Hypothalamic obesity in children. Obes Rev 2012; 13: 780-798.

2 Santos JL, Ho-Urriola JA, Gonzalez A, Smalley SV, Domínguez-Vásquez P, Cataldo R et al. Association between eating behavior scores and obesity in Chilean children. Nutr J 2011; 10: 108.

3 Scopinaro N, Adami GF, Papadia FS, Camerini G, Carlini F, Briatore L et al. The effects of biliopancreatic diversion on type 2 diabetes mellitus in patients with mild obesity (BMI $30-35 \mathrm{~kg} / \mathrm{m}^{2}$ ) and simple overweight $\left(B M I 25-30 \mathrm{~kg} / \mathrm{m}^{2}\right.$ ): a prospective controlled study. Obes Surg 2011; 21: 880-888.

4 Badran M, Laher I. Obesity in Arabic-speaking countries. J Obes 2011; 2011: 686430

5 Ogden CL, Carroll MD, Kit BK, Flegal KM. Prevalence of obesity and trends in body mass index among US children and adolescents, 1999-2010. JAMA 2012; 307: 483-490. 
6 Worldwide variation in prevalence of symptoms of asthma, allergic rhinoconjunctivitis, and atopic eczema: ISAAC. The International Study of Asthma and Allergies in Childhood (ISAAC) Steering Committee. Lancet 1998; 351: 1225-1232.

7 Anandan C, Nurmatov U, van Schayck OC, Sheikh A. Is the prevalence of asthma declining? Systematic review of epidemiological studies. Allergy 2010; 65: 152-167.

8 Anderson HR, Gupta R, Strachan DP, Limb ES. 50 years of asthma: UK trends from 1955 to 2004. Thorax 2007; 62: 85-90.

9 Bustos P, Amigo H, Oyarzun M, Rona RJ. Is there a causal relation between obesity and asthma? Evidence from Chile. Int J Obes 2005; 29: 804-809.

10 Shaheen SO. Obesity and asthma: cause for concern? Clin Exp Allergy 1999; 29: 291-293.

11 Tantisira KG, Weiss ST. Complex interactions in complex traits: obesity and asthma. Thorax 2001; 56(Suppl 2): ii64-ii73.

12 Camargo CA Jr, Weiss ST, Zhang S, Willett WC, Speizer FE. Prospective study of body mass index, weight change, and risk of adult-onset asthma in women. Arch Intern Med 1999; 159: 2582-2588.

13 Nystad W, Meyer HE, Nafstad P, Tverdal A, Engeland A. Body mass index in relation to adult asthma among 135,000 Norwegian men and women. Am J Epidemiol 2004; 160: 969-976.

14 Cassol VE, Rizzato TM, Teche SP, Basso DF, Centenaro DF, Maldonado M et al. Obesity and its relationship with asthma prevalence and severity in adolescents from southern Brazil. J Asthma 2006; 43: 57-60.

15 Noal RB, Menezes AM, Macedo SE, Dumith SC. Childhood body mass index and risk of asthma in adolescence: a systematic review. Obes Rev 2010; 12: 93-104.

16 Mamun AA, Lawlor DA, Alati R, O'Callaghan MJ, Williams GM, Najman JM. Increasing body mass index from age 5 to 14 years predicts asthma among adolescents: evidence from a birth cohort study. Int J Obes 2007; 31: 578-583.

17 Vangeepuram N, Teitelbaum SL, Galvez MP, Brenner B, Doucette J, Wolff MS Measures of obesity associated with asthma diagnosis in ethnic minority children. J Obes 2011; 2011: 517417.

18 Kajbaf TZ, Asar S, Alipoor MR. Relationship between obesity and asthma symptoms among children in Ahvaz, Iran: a cross sectional study. Ital J Pediatr 2011; 37: 1.

19 Mishra V. Effect of obesity on asthma among adult Indian women. Int J Obes Relat Metab Disord 2004; 28: 1048-1058.

20 Camargo CAJ, Wentowski C, Field A, Gillman M, Frazier A, Colditz G. Prospective cohort study of body mass index and risk of asthma in children. Ann Epidemiol 2003; 13: 565 .

21 Matricardi PM, Gruber C, Wahn U, Lau S. The asthma-obesity link in childhood: open questions, complex evidence, a few answers only. Clin Exp Allergy 2007; 37: 476-484.

22 Hill AB. The environment and disease: association or causation? Proc $R$ Soc Med 1965; 58: 295-300.

23 Shore SA. Obesity and asthma: lessons from animal models. J Appl Physiol 2007; 102: $516-528$

24 Shore SA. Obesity and asthma: possible mechanisms. J Allergy Clin Immunol 2008; 121: 1087-1093, quiz 94-5.

25 Hallstrand TS, Fischer ME, Wurfel MM, Afari N, Buchwald D, Goldberg J. Genetic pleiotropy between asthma and obesity in a community-based sample of twins. J Allergy Clin Immunol 2005; 116: 1235-1241.

26 Weiss ST, Shore S. Obesity and asthma: directions for research. Am J Respir Crit Care Med 2004; 169: 963-968.

27 Weiss ST. Obesity: insight into the origins of asthma. Nat Immunol 2005; 6 : 537-539.

28 Sood A. Sex differences: implications for the obesity-asthma association. Exerc Sport Sci Rev 2011; 39: 48-56.

29 Deesomchok A, Fisher T, Webb KA, Ora J, Lam YM, Lougheed MD et al. Effects of obesity on perceptual and mechanical responses to bronchoconstriction in asthma. Am J Resp Crit Care Med 2010; 181: 125-133.

30 Nahhas M, Bhopal R, Anandan C, Elton R, Sheikh A. Prevalence of allergic disorders among primary school-aged children in Madinah, Saudi Arabia: two-stage crosssectional survey. PLoS ONE 2012; 7: e36848.

31 Trasande L, Cronk C, Durkin M, Weiss M, Schoeller DA, Gall EA et al. Environment and obesity in the National Children's Study. Environ Health Perspect 2009; 117: 159-166.

32 Baker KM, Goetzel RZ, Pei X, Weiss AJ, Bowen J, Tabrizi MJ et al. Using a return-oninvestment estimation model to evaluate outcomes from an obesity management worksite health promotion program. J Occup Environ Med 2008; 50: 981-990.

33 Sole D, Vanna AT, Yamada E, Rizzo MC, Naspitz CK. International Study of Asthma and Allergies in Childhood (ISAAC) written questionnaire: validation of the asthma component among Brazilian children. J Investig Allergol Clin Immunol 1998; 8: 376-382.

34 Mohammad Y, Tabbah K, Mohammad S, Yassine F, Clayton T, Hassan M. International study of asthma and allergies in childhood: phase 3 in the Syrian Arab Republic. East Mediterr Health J 2010; 16: 710-716.

35 Bener A, Abdulrazzaq YM, Debuse P, Al-Mutawwa J. Prevalence of asthma among Emirates school children. Eur J Epidemiol 1994; 10: 271-278.

36 Janahi IA, Bener A, Bush A. Prevalence of asthma among Qatari schoolchildren: International Study of Asthma and Allergies in Childhood, Qatar. Pediatr Pulmonol 2006; 41: 80-86.

37 Stumvoll M, Tschritter O, Fritsche A, Staiger H, Renn W, Weisser M et al. Association of the T-G polymorphism in adiponectin (exon 2) with obesity and insulin sensitivity: interaction with family history of type 2 diabetes. Diabetes 2002; $\mathbf{5 1}$ : 37-41.

38 Tanner JM, Whitehouse RH, Takaishi M. Standards from birth to maturity for height, weight, height velocity, and weight velocity: British children, 1965. II. Arch Dis Child 1966; 41: 613-635.

39 Weiss M. Diabetes-renal failure-obesity-osteoporosis. How the thyroid gland controls metabolism. MMW Fortschritte der Medizin 2007; 149: 10-12.

40 Durnin JV, Womersley J. Body fat assessed from total body density and its estimation from skinfold thickness: measurements on 481 men and women aged from 16 to 72 years. Br J Nutr 1974; 32: 77-97.

41 Reilly JJ, Wilson J, Durnin JV. Determination of body composition from skinfold thickness: a validation study. Arch Dis Child 1995; 73: 305-310.

42 Hatipoglu N, Ozturk A, Mazicioglu MM, Kurtoglu S, Seyhan S, Lokoglu F. Waist circumference percentiles for 7- to 17-year-old Turkish children and adolescents. Eur J Pediatr 2008; 167: 383-389.

43 Miller MR, Crapo R, Hankinson J, Brusasco V, Burgos F, Casaburi R et al. General considerations for lung function testing. Eur Respir J 2005; 26: 153-161.

44 Clausen JL, Coates AL, Quanjer PH. Measurement of lung volumes in humans: review and recommendations from an ATS/ERS workshop. Eur Respir J 1997; 10: 1205-1206.

45 Beydon N, Davis SD, Lombardi E, Allen JL, Arets HG, Aurora P et al. An official American Thoracic Society/European Respiratory Society statement: pulmonary function testing in preschool children. Am J Resp Crit Care Med 2007; 175: 1304-1345.

46 Arshad SH, Tariq SM, Matthews S, Hakim E. Sensitization to common allergens and its association with allergic disorders at age 4 years: a whole population birth cohort study. Pediatrics 2001; 108: E33.

47 Bryant T. Confidence Interval Analysis (CIA), version 2 edn. BMJ Publishing Group: London, UK

48 Castro-Rodriguez JA, Holberg CJ, Morgan WJ, Wright AL, Martinez FD. Increased incidence of asthmalike symptoms in girls who become overweight or obese during the school years. Am J Respir Crit Care Med 2001; 163: 1344-1349.

49 Hancox RJ, Milne BJ, Poulton R, Taylor DR, Greene JM, McLachlan CR et al. Sex differences in the relation between body mass index and asthma and atopy in a birth cohort. Am J Respir Crit Care Med 2005; 171: 440-445.

50 Magnusson JÖ, Kull I, Mai XM, Wickman M, Bergström A. Early childhood overweight and asthma and allergic sensitization at 8 years of age. Pediatrics 2012; 129: $70-76$

51 Kannan S, Acosta LM, Acevedo-Garcia D, Divjan A, Bracero LA, Perzanowski MS et al. Sociocultural characteristics, obesity and inflammatory biomarkers in Puerto Rican toddlers born in New York City. Pediatr Allergy Immunol 2013; 24: 487-492.

52 Hersoug LG, Linneberg A. The link between the epidemics of obesity and allergic diseases: does obesity induce decreaded immune tolerance? Allergy 2007; 62: 1205-1213.

53 Guidotti TL. Applying the precautionary principle. Arch Environ Occup Health 2012; 67: 63-64.

54 Freedman DS, Mei Z, Srinivasan SR, Berenson GS, Dietz WH. Cardiovascular risk factors and excess adiposity among overweight children and adolescents: the Bogalusa Heart Study. J Pediatr 2007; 150: 12-7 e2.

This work is licensed under a Creative Commons Attribution 4.0 International License. The images or other third party material in this article are included in the article's Creative Commons license, unless indicated otherwise in the credit line; if the material is not included under the Creative Commons license, users will need to obtain permission from the license holder to reproduce the material. To view a copy of this license, visit http://creativecommons.org/ licenses/by $/ 4.0$ 